\title{
Password Based Distribution Panel and Circuit Breaker Operation for the Safety of Lineman during Maintenance Work
}

\author{
Mallikarjun G. Hudedmani*, Nitin Ummannanavar, Mani Dheeraj Mudaliar, \\ Chandana Sooji, Mala Bogar \\ Department of Electrical and Electronics Engineering, KLE Institute of Technology, \\ Opposite to Airport, Gokul, Hubballi, Karnataka, India
}

doi: https://doi.org/10.21467/ajgr.1.1.35-39

* Corresponding Author email: mallikarjunh@yahoo.com

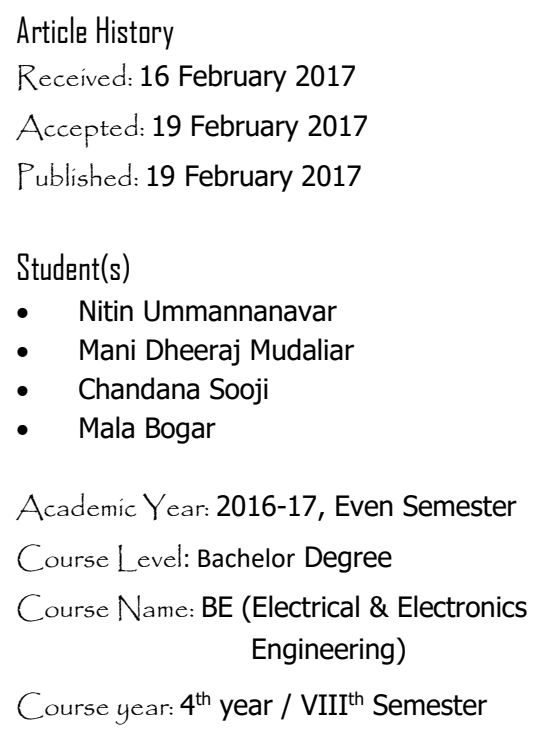

\begin{abstract}
Security is the prime concern in our day to day life while performing any activity. In the current scenario, accidental death of lineman is often read and evidenced. In this direction, a safety measure to safe guard the operator is found very necessary looking into the present working style. The electric lineman safety system is designed to control the control panel doors and circuit breaker by using a password for the safety. Critical electrical accidents to lineman are on the rise during electric line repair may be due to lack of communication and co-ordination between the maintenance staff and electric substation staff. The proposed system provides a solution that ensures safety of lineman. The control to turn $\mathrm{ON}$ or OFF the line is maintained by the lineman. The system has an arrangement such that a password is required to operate the doors of the control panel and circuit breaker (ON/OFF). A secured password is requested and received from the control room by the lineman for the point of repair or service. This request is registered and a password is sent to the lineman's mobile and control panel GSM module for the further work. The password is entered through the matrix keypad which is interfaced to the Arduino Uno microcontroller. The entered password is compared with the password received by the control panel GSM receiver. If the entered password is correct then the circuit breaker ON/OFF and door OPEN/CLOSE feature is enabled for the lineman to take up repair. Any intruder tries to operate the mechanism with the wrong password by three times it will display a message in the LCD display and a message is sent to the control room regarding unauthorized accessing of the system for the safety reasons.
\end{abstract}

Keywords: Lineman safety, GSM, Password security, Arduino controller, Circuit breaker control. 


\section{Introduction}

The electrical energy is the clean and cheapest form of energy for the specific needs of domestic, corporate and industrial consumers. The electric distribution is a very wide network of wires to deliver the supply by incorporating various electrical elements. Presently the accidental cases of death or injuries of linemen is noticed while working on the section of line for the repair or maintenance. The present work focuses on the regular practice and flaws of line clearance (LC) for the repair request and closing of LC after the repair is done. The draw backs of current LC system are charging of the line by accidental or by mistake of the operators at substation may be due to lack of information or criticality has evidenced injuries or even death of working linemen on the line. The use of intelligent micro controllers for various control mechanisms is found in the literature [1]. The use of communication networks increases the efficiency of the remote-controlled objects or devices. The GSM technology connects the end device from remote and provides an opportunity to control [2]. The proposed low cost Arduino controlled GSM message based secured password operated control panel and circuit breaker ON/OFF is the best suited mechanism in preventing the injuries or death of working men on the line by any accidental charging of line un knowingly [3]. The unauthorized access of the secured systems is prevented by authorization password or login for the security purpose. The lack of communication and co-ordination between the maintenance staff and the electric substation staff can be minimized. This system provides a solution to ensure the safety of the maintenance staff [4]-[6].

\section{Construction and Working of the Proposed Model}

\subsection{Proposed Model}

The model is constructed around Arduino UNO microcontroller and GSM module interfaced with that at transformer control panel. The matrix keypad, LED indicators and stepper motor driven by microcontroller for the door operation are arranged around the controller. The control centre is assumed as a mobile to receive and send password to the lineman's mobile and GSM receiver of the control panel. The work mainly focuses on the distribution transformer control panel and circuit breaker. The opening of doors of the control panel is presently simple and much more doors normally open in the present scenario. This is very dangerous and results accidental disasters.

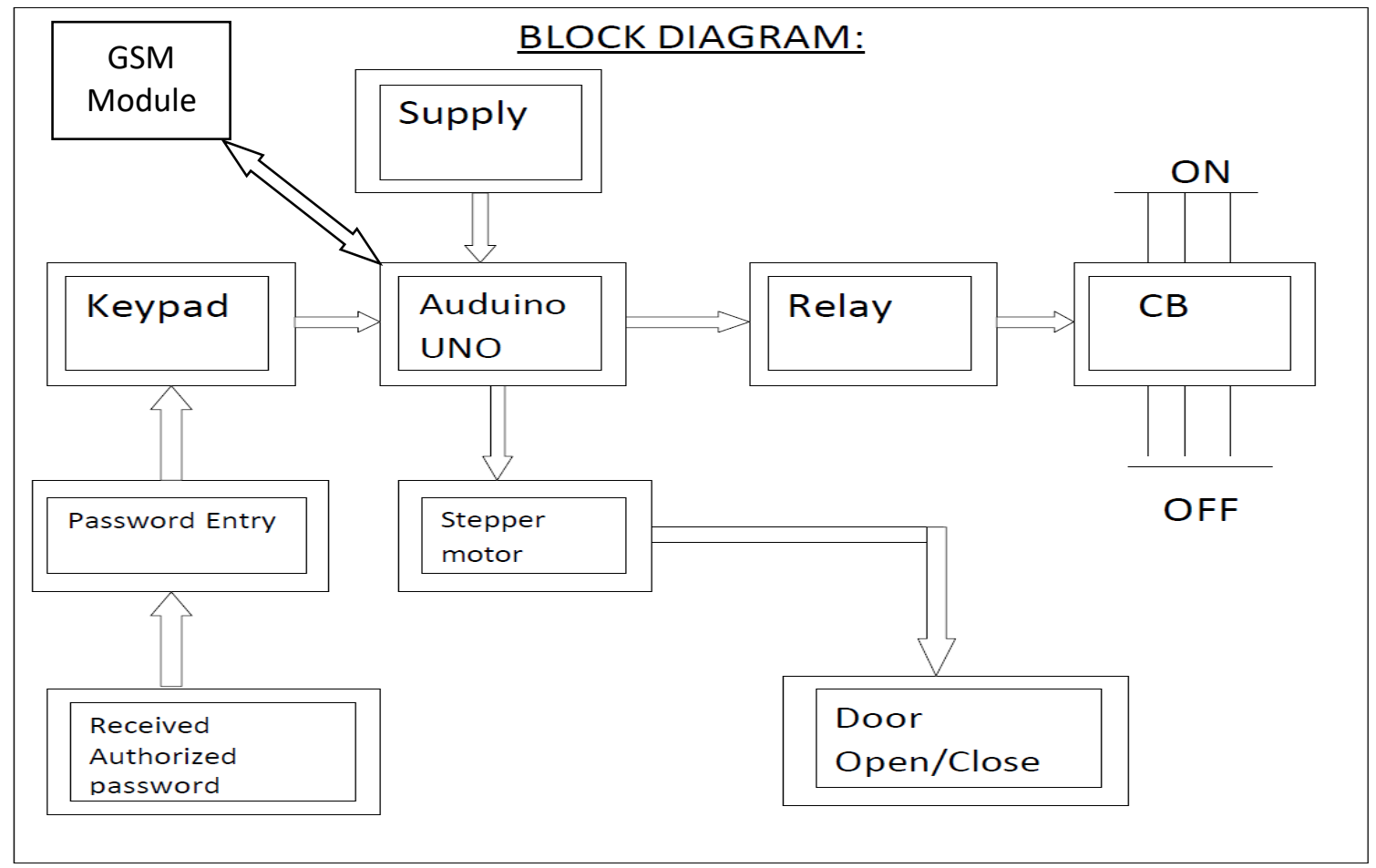

Figure 1: Block diagram of the proposed model 
Hudedmani et al., Adv. J. Grad. Res.; Vol. 1 Issue 1, pp: 35-39, January 2017

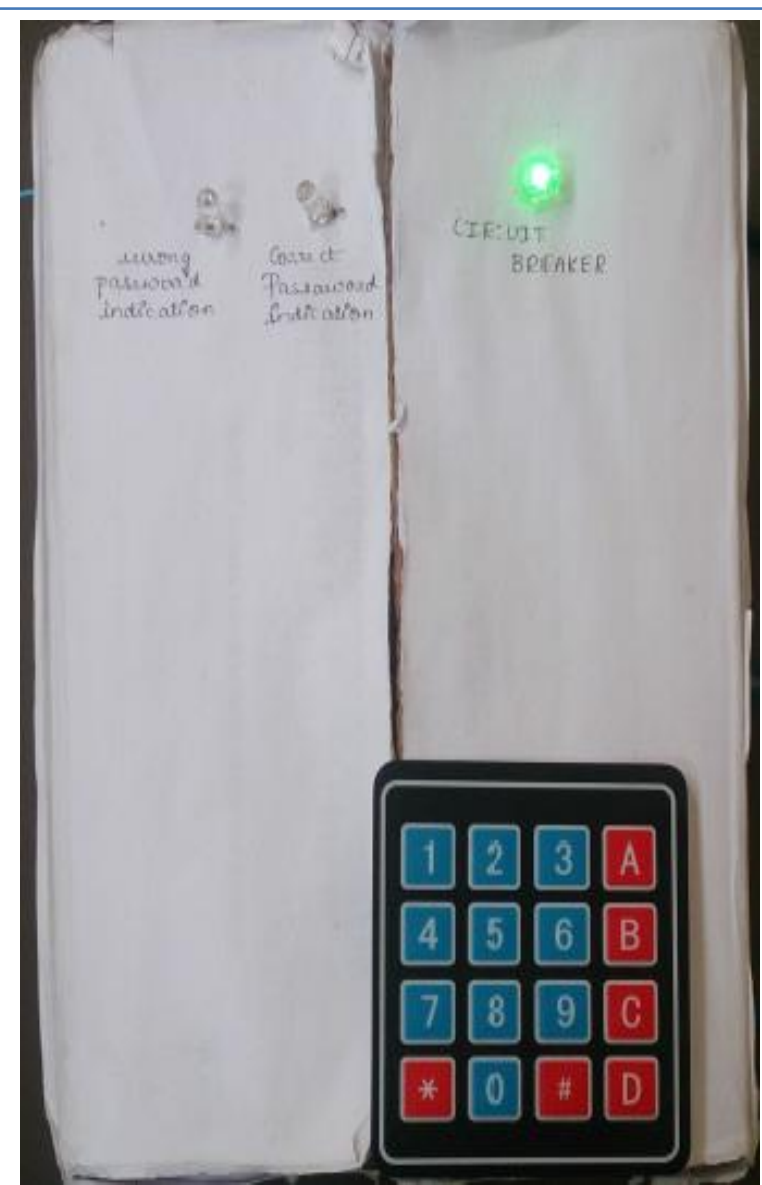

Figure 2: Physical model of the proposed concept

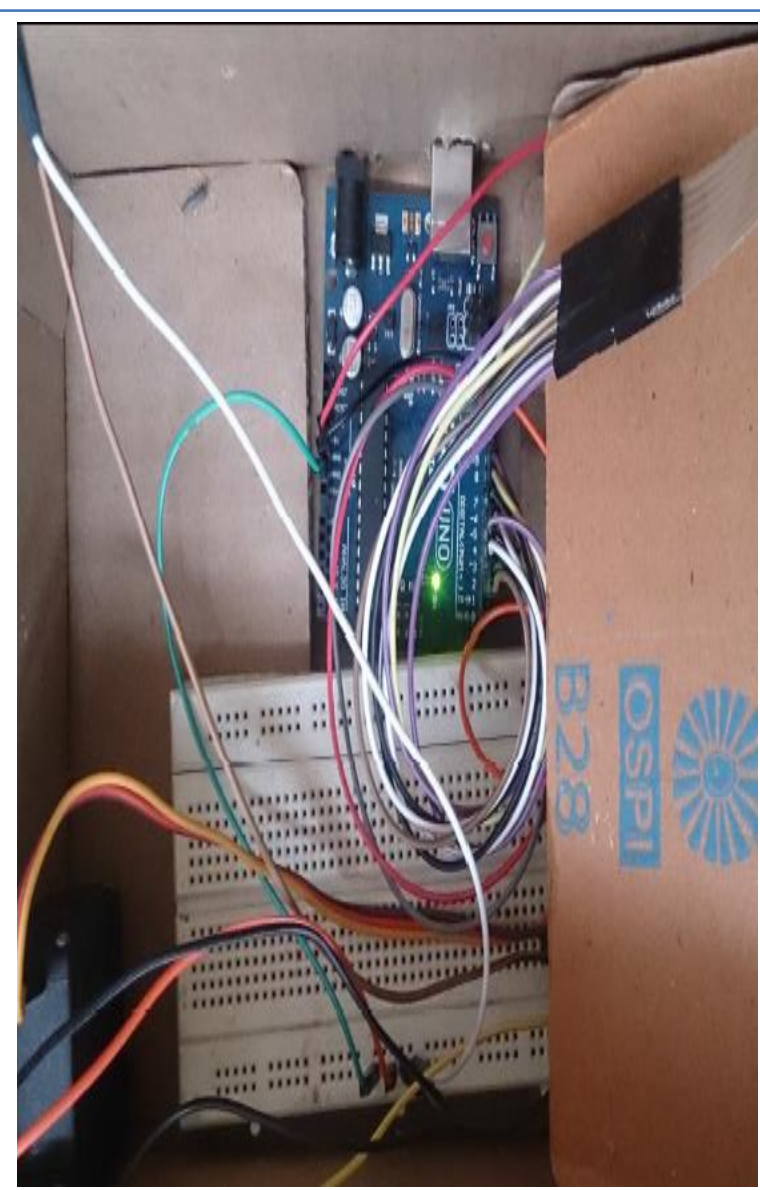

Figure 3: Component view of the proposed model

The concept proposes the control of the panel doors automatically by a stepper motor. The opening and closing is only after the verification of secured password by the user or lineman. The opening of the panel door is interlocked with circuit breakers ON/OFF condition for the safety reasons. The door can be opened only in the OFF state of the circuit breaker. Circuit breaker is an electrical switch designed to protect an electrical circuit from damage caused by over current/overload or faults. Its basic function is to interrupt current flow after the detection of fault by the relay. Unlike a fuse, which operates once and then must be replaced the circuit breaker can be reset (either manually or automatically) to resume normal operation. Circuit breakers are made in varying sizes from small devices that protect individual household appliances up to large switchgear designed to protect high voltage circuits feeding an entire city. Block diagram of the proposed model is shown in Figure 1. Physical working model photographs are shown in Figure 2 and Figure 3.

\subsection{Working of the Model}

The working procedure of the model begins with the service request by the area lineman to the control room for a secured password to switch off the circuit breaker and open the doors of the specified control panel. The control room operator acknowledges the request and sends a secured password to the control panel GSM receiver and to the lineman's mobile. Only after the entry of correct password the circuit breaker is turned OFF by the controller before opening the panel doors. A relay is simulated as a circuit breaker for ease of demonstration. The status is indicated by LEDs and message on LCD display allowing to the service or repair activity by the lineman without any doubt with security. The turn ON of the circuit breaker is interlocked with the closure of the panel doors for the safety reasons. On the completion of the repair or service the lineman sends a request for the password to turn ON the circuit 
breaker from the control room. On verification of the true password and door condition circuit breaker turns $\mathrm{ON}$. This method provides greater safety and assurance to the lineman on work.

\subsection{List of Components}

Following table provide list main components used in the work.

Table 1: List of main components used in the work

\begin{tabular}{|c|c|c|c|}
\hline S.No & Components & Features & Specification \\
\hline \multirow{7}{*}{1.} & \multirow{7}{*}{ Arduino } & Opearting Voltage & $5 \mathrm{~V}$ \\
\hline & & Input Voltage & $7 \mathrm{~V} \mathrm{TO} 12 \mathrm{~V}$ \\
\hline & & Digital I/O Pin & 14 \\
\hline & & Analog I/O Pin & 6 \\
\hline & & DC Current/ Input Pin & $40 \mathrm{~mA}$ \\
\hline & & Flash Memory & $32 \mathrm{~KB}$ \\
\hline & & Clock Speed & $16 \mathrm{MHz}$ \\
\hline \multirow{6}{*}{2.} & \multirow{6}{*}{ Servo Motor } & Operating Voltage & $4.8 \mathrm{~V} \mathrm{TO} 6$ \\
\hline & & Operating Speed & $\begin{array}{l}0.20 \mathrm{sec} / 60 \text { for } 4.8 \mathrm{~V} \\
0.16 \mathrm{sec} / 60 \text { for } 6 \mathrm{~V}\end{array}$ \\
\hline & & Stall Torque & $\begin{array}{l}5.3 \mathrm{Kg} \mathrm{Cm}(4.8) \\
7 \mathrm{Kg} \mathrm{cm}(6 \mathrm{~V})\end{array}$ \\
\hline & & Temperature Range & $20^{\circ} \mathrm{C}$ TO $60^{\circ} \mathrm{C}$ \\
\hline & & Dimension & $41 X 20 X 38 \mathrm{~mm}$ \\
\hline & & Weight & $41 \mathrm{~g}$ \\
\hline \multirow{3}{*}{3.} & \multirow{3}{*}{ Relay } & Operating Current & $5 \mathrm{~A}$ \\
\hline & & Operating Voltage & $6 V_{D C}$ \\
\hline & & Frequency & $50 \mathrm{~Hz}$ \\
\hline 4. & Resistor & - & $1 \mathrm{~K} \Omega$ \\
\hline 5. & Keypad & - & 4X4 Matrix \\
\hline
\end{tabular}

\section{Pros and Cons of the Proposed System}

Following are the few pros and cons of the proposed system listed to show the effective working of the model and followed by typical applications.

- Concept is simple, economical and easy to implement as it uses commonly available components.

- Avoids electrical accidents to lineman and also electrical equipment's.

- Ease of operation, maintenance and repair.

- Concept works on a secured password which can be modified easily.

- Dependency on GSM network and reliability of the same.

- Additional hardware need to be interfaced and implemented in the control panel

- On the loss of password system cannot be operated and need a change in password request to the control substation.

- Increased dependency of the concept. A failure or malfunction of the components leads to interruption of service.

\section{Conclusions}

The ARDUINO microcontroller and GSM based work demonstrate the security of the lineman as switching ON/OFF of circuit breaker and opening or closing of control panel door is done for the purpose of repair or maintenance. The method overcomes the deficiency of existing system of LC opening and closing request for the line. The secured authentic password from the substation to the 
Hudedmani et al., Adv. J. Grad. Res.; Vol. 1 Issue 1, pp: 35-39, January 2017

working lineman ensures the operation of the panel doors and circuit breaker for the beginning of work. Similarly, a request to close the lines after the work by authentic password and charging up of the line by the substation operators is done. The method double cross checks the completion and ensures the safety. Any unauthorized access into the system by wrong password for specific number of trials send a message to the LCD display and a message to substation for the security purpose.

\section{How to cite this article:}

Hudedmani, M., Ummannanavar, N., Mudaliar, M., Sooji, C., \& Bogar, M. (2017). Password Based Distribution Panel and Circuit Breaker Operation for the Safety of Lineman during Maintenance Work. Advanced Journal of Graduate Research, 1(1), 35-39.

doi: https://doi.org/10.21467/ajgr.1.1.35-39

\section{References}

[1] Viral P. Solanki, Ajit J. Parmar, Nikul S. Limbachiya, Rakesh Koringa, and Shivangi Patel, “Arduino Based Protection System for Wireman," Int. J. Electr. Electron. Res., vol. 3, no. 1, pp. 76-79, 2015.

[2] J.Veena, G.Srivani, Afreen, M.Sunil Kumar, J.Santhosh, and K.B.V.S.R.Subrahmanyam, "Electric Lineman Protection Using User Changeable Password Based Circuit Breaker," Int. J. Curr. Eng. Sci. Res., vol. 2, no. 5, pp. 44-49, 2015.

[3] P. N. Mahadik, P. A. Yadav, S. B. Gotpagar, and H. P. Pawar, "Electric Line Man Safety using Micro Controller with GSM Module," Int. J. Sci. Res. Dev., vol. 4, no. 1, pp. 205-207, 2016.

[4] A. M. Hassan Ali, "Enhancement of a GSM Based Control System," in Advances in Circuits, Systems, Signal Processing and Telecommunications , 2015, pp. 189-202.

[5] D. R. Brooks, "Arduino-Based Dataloggers: Hardware and Software," 1.3, 2016.

[6] A. M. Gibb, "New Media Art, Design, And The Arduino Microcontroller: A Malleable Tool," School of Art and Design, Pratt Institute, 2010

\section{Publish your research article in AIJR journals-}

$\checkmark \quad$ Online Submission and Tracking

$\checkmark$ Peer Reviewed

$\checkmark$ Rapid decision

$\checkmark$ Immediate Publication after acceptance

$\checkmark$ Open Access (Articles freely available online)

$\checkmark$ Retain full copyright of your article.

Submit your article at journals.aijr.in 